\title{
Vegetation effects on mean daily maximum and minimum surface air temperatures over China
}

\author{
WU LingYun ${ }^{1 \dagger}$, ZHANG JingYong ${ }^{1 * \dagger} \&$ DONG WenJie ${ }^{2}$ \\ ${ }^{1}$ Center for Monsoon System Research, Institute of Atmospheric Physics, Chinese Academy of Sciences, Beijing 100029, China; \\ ${ }^{2}$ State Key Laboratory of Earth Surface Processes and Resource Ecology, Beijing Normal University, Beijing 100875, China
}

Received October 9, 2010; accepted December 23, 2010

\begin{abstract}
Changes in the daily maximum $\left(T_{\max }\right)$ and minimum $\left(T_{\min }\right)$ surface air temperatures and the associated temperature extremes have severe consequences on human society and the natural environment. In this study, we assess vegetation effects on mean $T_{\max }$ and $T_{\min }$ over China by computing a vegetation feedback parameter using the satellite-sensed Normalized Difference Vegetation Index (NDVI) and observed temperatures for the period 1982-2002. In all seasons, vegetation exerts a much stronger forcing on $T_{\max }$ than on $T_{\min }$, and thus has a substantial effect on the diurnal temperature range (DTR) over China. Significant positive feedbacks on $T_{\max }$ and the DTR occupy many areas of China with the feedback parameters exceeding $1{ }^{\circ} \mathrm{C}(0.1 \mathrm{NDVI})^{-1}$, while significant negative effects only appear over the summertime climatic and ecological transition zone of northern China and some other isolated areas. Also, the vegetation feedbacks are found to vary with season. In areas where significant feedbacks occur, vegetation contributes to typically $10 \%-30 \%$ of the total variances in $T_{\max }, T_{\min }$, and the DTR. These findings suggest that vegetation memory offers the potential for improving monthly-to-seasonal forecasting of $T_{\max }$ and $T_{\min }$, and the associated temperature extremes over China. Meanwhile, the limitations and uncertainties of the study should be recognized.
\end{abstract}

vegetation feedbacks, daily maximum temperature, daily minimum temperature, Normalized Difference Vegetation Index

Citation: Wu L Y, Zhang J Y, Dong W J. Vegetation effects on mean daily maximum and minimum surface air temperatures over China. Chinese Sci Bull, 2011, 56: 900-905, doi: 10.1007/s11434-011-4349-7

Vegetation can affect the climate through exchanges of heat, moisture, trace gases, aerosols, and momentum between the land surface and the overlying atmosphere on a variety of temporal and spatial scales [1]. Current understanding is largely based on model simulations [2]. For example, numerical experiments showed that the deforestation at mid-latitudes has cooled the Northern Hemisphere climate through biogeophysical effects $[3,4]$. However, large uncertainties exist in current model simulations of landatmosphere interactions, and varied and conflicting results often arise among different models, especially regarding local-to-regional land surface feedbacks [5,6].

Recently, some studies have attempted to infer the effect of vegetation on the climate from observational records

\footnotetext{
*Corresponding author (email: zjy@ mail.iap.ac.cn)

${ }^{\dagger}$ These authors contributed equally to the work.
}

[7-11]. It is suggested that over many areas of China, vegetation exerts positive effects on the monthly mean surface air temperature $[8,12]$. However, vegetation feedbacks on the mean daily maximum $\left(T_{\max }\right)$ and minimum $\left(T_{\min }\right)$ temperatures are not yet well understood from observations. This issue is of great importance since $T_{\max }$ and $T_{\min }$, and the associated temperature extremes, produce larger impact on human society and the natural environment than the average temperatures do $[13,14]$.

Here, we statistically assess vegetation effects on the mean $T_{\max }$ and $T_{\min }$ and also the diurnal temperature range (DTR) over China by calculating a vegetation feedback parameter using the satellite-sensed Normalized Difference Vegetation Index (NDVI) [15,16] and the China Homogenized Historical Temperature (CHHT) dataset [17] for the period 1982-2002. 


\section{Data and method}

We use monthly Global Inventory Modeling and Mapping Studies (GIMMS) satellite drift corrected and NOAA-16 incorporated NDVI data for the period of 1982-2002 at a resolution of $0.25^{\circ} \times 0.25^{\circ}[15,16]$. The NDVI is the difference between AVHRR reflectance in near-infrared and visible bands divided by the sum of these two bands. Data corrections were performed to reduce the effects not related to actual vegetation change [16].

The monthly averaged $T_{\max }$ and $T_{\min }$ data for the same period are taken from the CHHT dataset Version 1.0 [17]. The DTR is defined as the difference between mean $T_{\max }$ and $T_{\min }$. The CHHT 1.0 dataset was developed using daily observations from a total of 731 national weather stations over mainland China. The raw station data were assessed and corrected through rigorous and objective homogeneity adjustments by the National Meteorological Information Centre (NMIC). These adjustments reduced the nonclimatic errors or biases, thus improving the quality and reliability of the data.

The gridded NDVI data are first processed to stations by using values at the nearest grid point. We then remove the stations that have any missing values or are located in grid cells classified as water in the GIMMS data. The monthly anomalies of both NDVI and temperatures are further calculated as the departures from their climatological annual cycles. Finally, the data are linearly detrended.

A variance method that is initially proposed by Frankignoul and Hasselmann [18] is employed to quantify vegetation feedbacks on $T_{\max }, T_{\min }$, and the DTR. The method was previously applied to examine oceanic feedbacks on air-sea heat flux and atmosphere [19,20] and vegetation and soil moisture feedbacks on temperatures and precipitation $[8,21]$.

A given temperature variable at the time of $t+d t_{a}$ is assumed to be determined by the vegetation feedback and the atmospheric noise generated internally by atmospheric processes that are independent of the vegetation variability:

$$
T\left(t+d t_{a}\right)=\lambda_{T} V(t)+N\left(t+d t_{a}\right) .
$$

$T(t)$ is the anomaly of a given temperature variable, $V(t)$ is the vegetation anomaly, $\lambda_{T}$ is the feedback parameter or efficiency, $d t_{a}$ is the atmospheric response time, and $N(t)$ is the climate noise.

We eliminate the noise term by multiplying both sides of eq. (1) with $V(t-\tau)$ and taking the covariance following the same procedure in Frankignoul et al. [19]. Here $\tau$ is the time vegetation leads the atmosphere. Since the atmospheric response is usually fast, $\tau$ ( 1 month in this study) is much longer than the atmospheric response time, we neglect the atmospheric response time $\left(d t_{a}\right)$. Finally, the feedback parameter or efficiency $[8,19]$ is computed as

$$
\lambda_{T}=\frac{\operatorname{Cov}(V(t-\tau), T(t))}{\operatorname{Cov}(V(t-\tau), V(t))},
$$

where $\operatorname{Cov}(V(t-\tau), T(t))$ and $\operatorname{Cov}(V(t-\tau), V(t))$ represent the lagged covariance between the vegetation and temperature variable and the lagged covariance of the vegetation, respectively. Physically, the feedback parameter reflects the instantaneous response of a temperature variable to a change in vegetation when the atmospheric adjustment is neglected. While Liu et al. [8] used $\tau$ to quantify vegetation feedbacks on mean precipitation and temperature, we apply the statistical approach to assess vegetation effects on $T_{\max }$, $T_{\min }$, and the DTR. In this study, the monthly feedback parameter is calculated as the ratio of lagged covariance between a vegetation anomaly in the previous month and a given temperature variable in the present month to lagged vegetation auto-variance.

To test the robustness of the feedback parameter, we assess the statistical significance using a bootstrap approach [22]. We calculate 1000 individual $\lambda_{T}$ using temperature series derived from random permutations of the original ones. We judge the significance of the feedback parameter at the $90 \%$ confidence level. The percentage of the variance of monthly temperature anomalies attributed to vegetation feedback is computed as $\sigma^{2}\left(\lambda_{T} V\right) / \sigma^{2}(T)$, where $\sigma^{2}\left(\lambda_{T} V\right)$ and $\sigma^{2}(T)$ represent the variance of monthly temperature anomalies owing to vegetation feedback and the total variance of monthly temperature anomalies, respectively.

It should be noted that there are some limitations and uncertainties in the employed method [8,21]. To test the reliability of the variance method, Notaro et al. [23] and Notaro and Liu [24] assessed vegetation feedbacks on the climate for mid-Holocene North African grasslands and North Asian boreal forests using both the statistical approach and numerical simulations. The close agreement between the results of the two methods in their studies gives credence to the simple statistical approach to quantify vegetation feedbacks on the climate. Although a series of corrections were performed to the NDVI data, some biases still exist particularly over the areas with low vegetation coverage [16]. Our estimates, therefore, may be thought of as illustrative rather than definitive.

\section{Results}

Figure 1 shows seasonal mean vegetation feedback parameters for $T_{\max }, T_{\min }$ and the DTR. For a given season, the mean vegetation feedback parameters are produced by averaging the three monthly ones. For all seasons, vegetation effects on $T_{\max }$ are predominantly positive. Meanwhile, the vegetation feedbacks vary with season. In winter, significant positive feedbacks on $T_{\max }$ mainly appear over the climatic and ecological transition zone of northern China, the 
eastern Tibetan Plateau, and Southeast China. Springtime vegetation variations have significant and positive effects on $T_{\max }$ over many areas of Northeast China and southern China. In summer, significant positive feedbacks on $T_{\max }$ mainly occupy the Yangtze River valley. While vegetation feedbacks on $T_{\max }$ are mostly positive during the autumn-time over China, stations which pass the $90 \%$ confidence level are relatively scattered compared to the other three seasons. In contrast, significant negative feedbacks on $T_{\max }$ only occur over the summertime climatic and ecological transition zone of northern China and some other isolated areas.
For all seasons, vegetation effects on $T_{\min }$ are less positive relative to $T_{\max }$. Especially during the summertime when vegetation effects are predominantly negative, significant positive feedbacks only exist over the lower reaches of the Yangtze River and some other isolated areas. The magnitudes of vegetation feedbacks on $T_{\min }$ are generally much smaller than those for $T_{\max }$. As a result, vegetation has a substantial effect on the DTR mainly through its effects on $T_{\max }$. In terms of both spatial patterns and the magnitudes, vegetation feedbacks on the DTR are largely similar to the feedbacks on $T_{\max }$. In the meanwhile, some differences

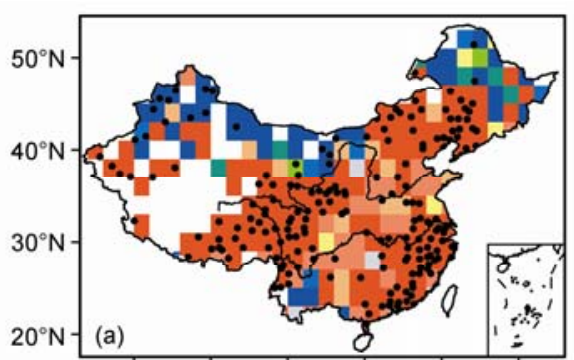

$80^{\circ} \mathrm{E} \quad 90^{\circ} \mathrm{E} 100^{\circ} \mathrm{E} 110^{\circ} \mathrm{E} 120^{\circ} \mathrm{E} 130^{\circ} \mathrm{E}$
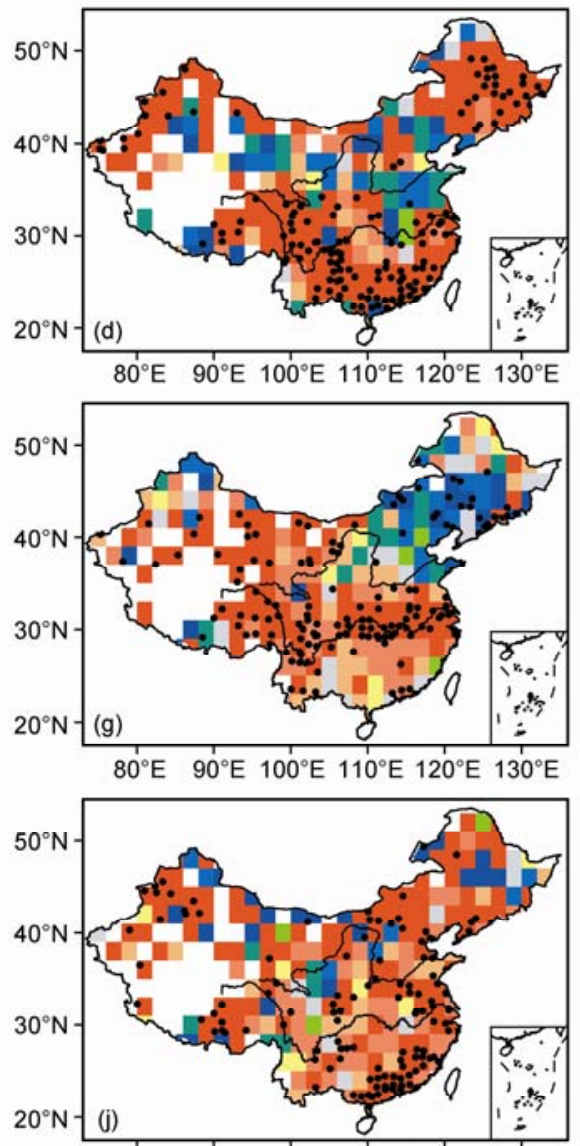

$80^{\circ} \mathrm{E} \quad 90^{\circ} \mathrm{E} 100^{\circ} \mathrm{E} 110^{\circ} \mathrm{E} 120^{\circ} \mathrm{E} 130^{\circ} \mathrm{E}$

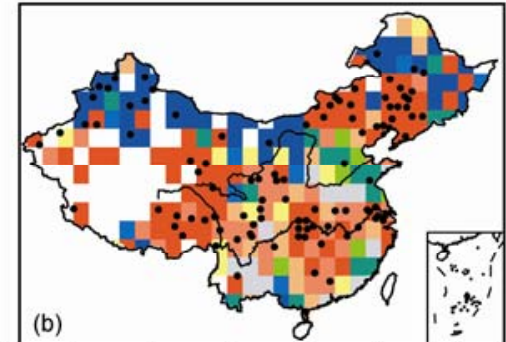

$80^{\circ} \mathrm{E} \quad 90^{\circ} \mathrm{E} 100^{\circ} \mathrm{E} 110^{\circ} \mathrm{E} 120^{\circ} \mathrm{E} 130^{\circ} \mathrm{E}$

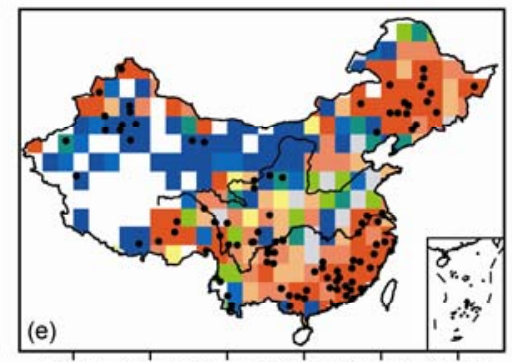

$80^{\circ} \mathrm{E} \quad 90^{\circ} \mathrm{E} \quad 100^{\circ} \mathrm{E} \quad 110^{\circ} \mathrm{E} 120^{\circ} \mathrm{E} 130^{\circ} \mathrm{E}$

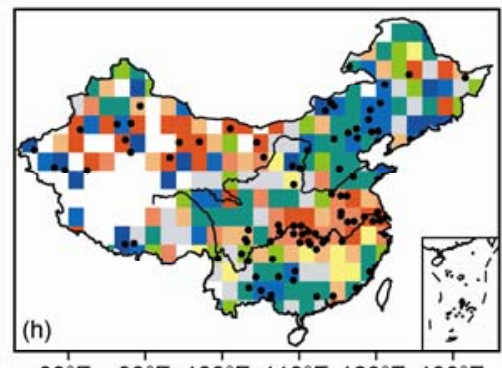

$80^{\circ} \mathrm{E} \quad 90^{\circ} \mathrm{E} 100^{\circ} \mathrm{E} 110^{\circ} \mathrm{E} 120^{\circ} \mathrm{E} 130^{\circ} \mathrm{E}$

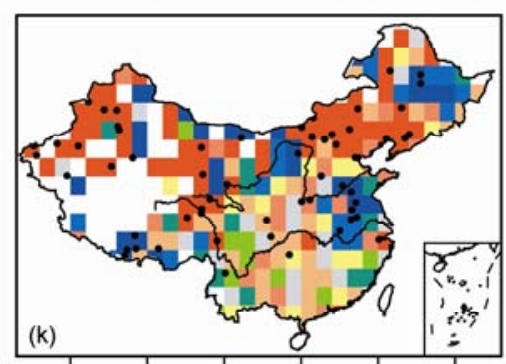

$80^{\circ} \mathrm{E} \quad 90^{\circ} \mathrm{E} 100^{\circ} \mathrm{E} 110^{\circ} \mathrm{E} 120^{\circ} \mathrm{E} 130^{\circ} \mathrm{E}$

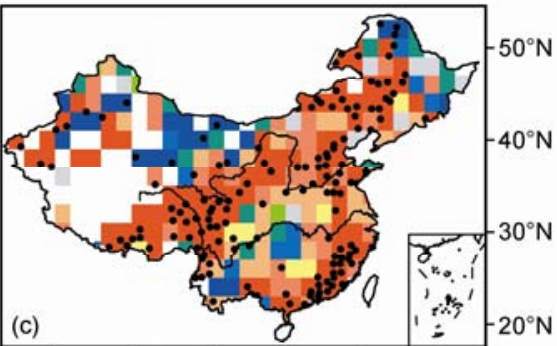

$80^{\circ} \mathrm{E} \quad 90^{\circ} \mathrm{E} \quad 100^{\circ} \mathrm{E} 110^{\circ} \mathrm{E} 120^{\circ} \mathrm{E} 130^{\circ} \mathrm{E}$

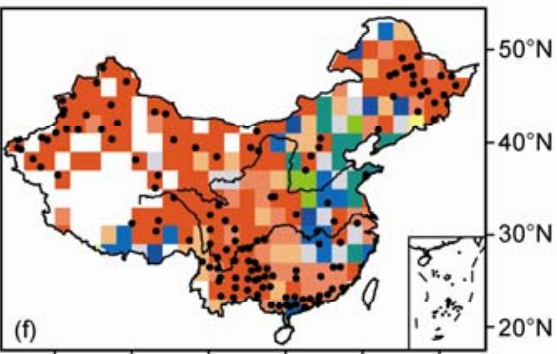

$80^{\circ} \mathrm{E} \quad 90^{\circ} \mathrm{E} \quad 100^{\circ} \mathrm{E} 110^{\circ} \mathrm{E} 120^{\circ} \mathrm{E} 130^{\circ} \mathrm{E}$

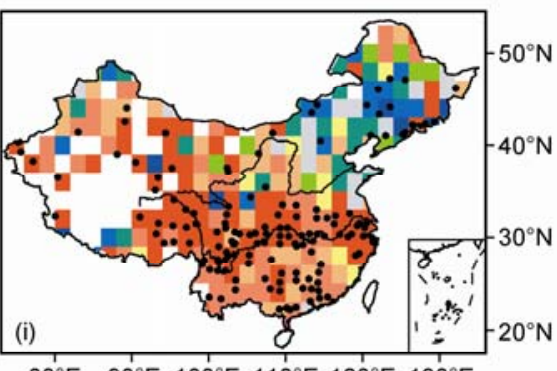

$80^{\circ} \mathrm{E} \quad 90^{\circ} \mathrm{E} \quad 100^{\circ} \mathrm{E} 110^{\circ} \mathrm{E} 120^{\circ} \mathrm{E} 130^{\circ} \mathrm{E}$

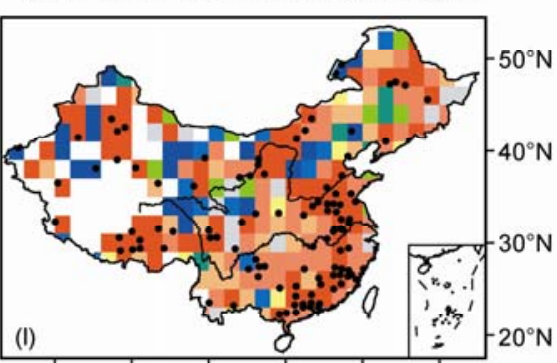

$80^{\circ} \mathrm{E} \quad 90^{\circ} \mathrm{E} 100^{\circ} \mathrm{E} 110^{\circ} \mathrm{E} 120^{\circ} \mathrm{E} 130^{\circ} \mathrm{E}$

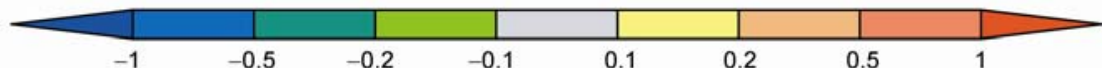

Figure 1 Seasonal mean of monthly vegetation feedback parameters (in $\left.{ }^{\circ} \mathrm{C}(0.1 \mathrm{NDVI})^{-1}\right)$ for the mean daily maximum (left panel), minimum (middle panel) and diurnal range (right panel) of surface air temperature for the period 1982-2002: (a)-(c) DJF; (d)-(f) MAM; (g)-(i) JJA; (j)-(l) SON. Stations with values that achieve $P<0.1$ are marked by circles. Station values of the vegetation feedback parameter are binned into $2^{\circ} \times 2^{\circ}$ grid cells. 
exist. For example, the springtime vegetation feedbacks on the DTR over some areas of Northwest China are largely dependent on the effects on $T_{\min }$ rather than those on $T_{\max }$. Over regions that achieve $P<0.1$, the magnitudes of the feedbacks on $T_{\max }, T_{\min }$, and the DTR are generally larger than $1^{\circ} \mathrm{C}(0.1 \mathrm{NDVI})^{-1}$.

Figure 2 presents seasonal mean percent variances in $T_{\max }, T_{\min }$, and the DTR owing to vegetation feedbacks over China. The feedback-induced variability typically accounts for $10 \%-30 \%$ of the total variances in $T_{\max }, T_{\min }$, and the
DTR over regions where the $90 \%$ statistical significance is achieved. Over the rest of China, the percentages are low, generally less than $10 \%$. It should be noted that other land surface parameters also can affect the temperatures through their effects on the surface energy balance, vegetation growth, and other processes. For example, soil moisture can alter evapotranspiration, thus affecting the surface air temperatures. Also, vegetation is typically limited by soil moisture over arid and semiarid areas of China. Snow is another critical land surface parameter, and can affect surface air
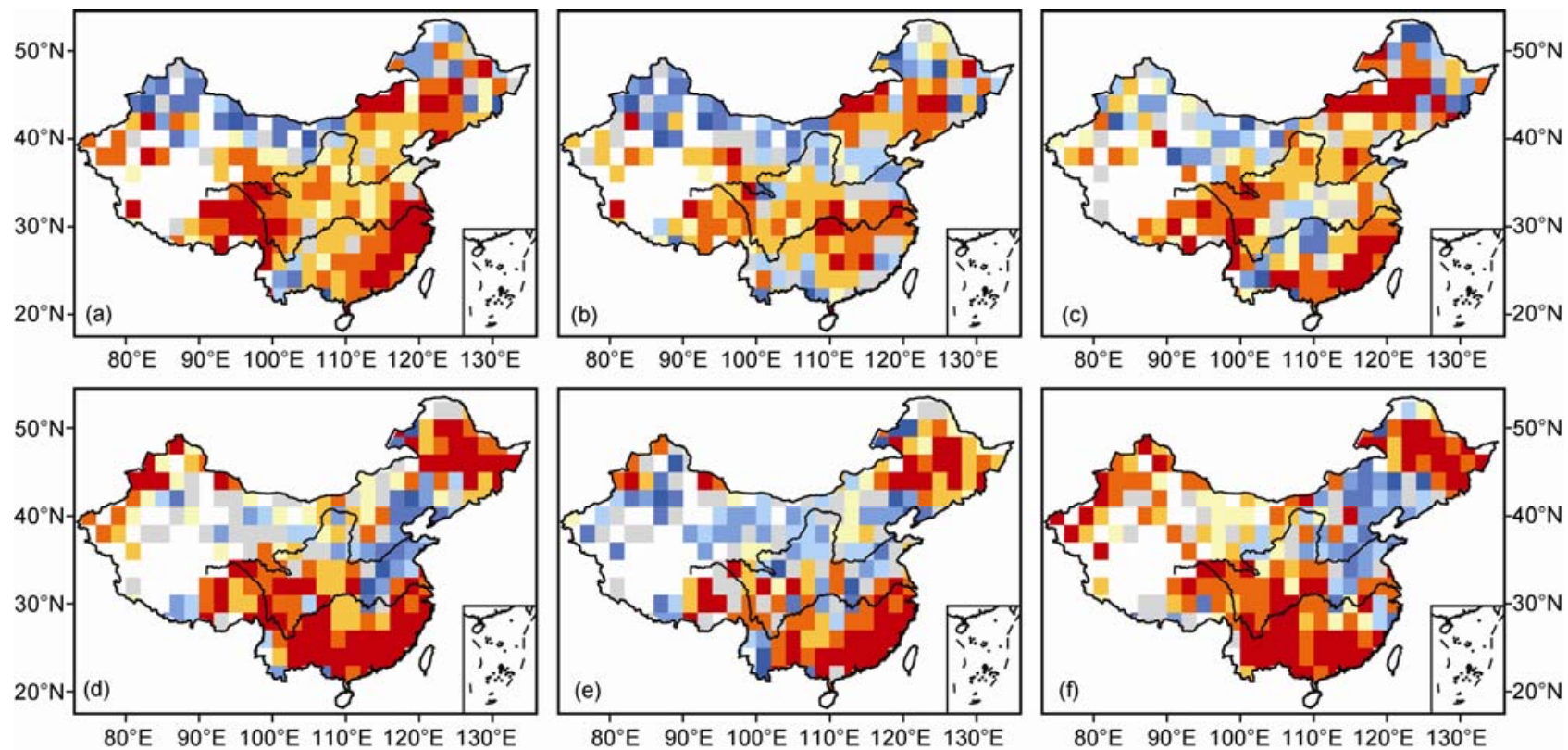

$80^{\circ} \mathrm{E} \quad 90^{\circ} \mathrm{E} \quad 100^{\circ} \mathrm{E} 110^{\circ} \mathrm{E} 120^{\circ} \mathrm{E} 130^{\circ} \mathrm{E}$

$80^{\circ} \mathrm{E} \quad 90^{\circ} \mathrm{E} \quad 100^{\circ} \mathrm{E} 110^{\circ} \mathrm{E} 120^{\circ} \mathrm{E} 130^{\circ} \mathrm{E}$
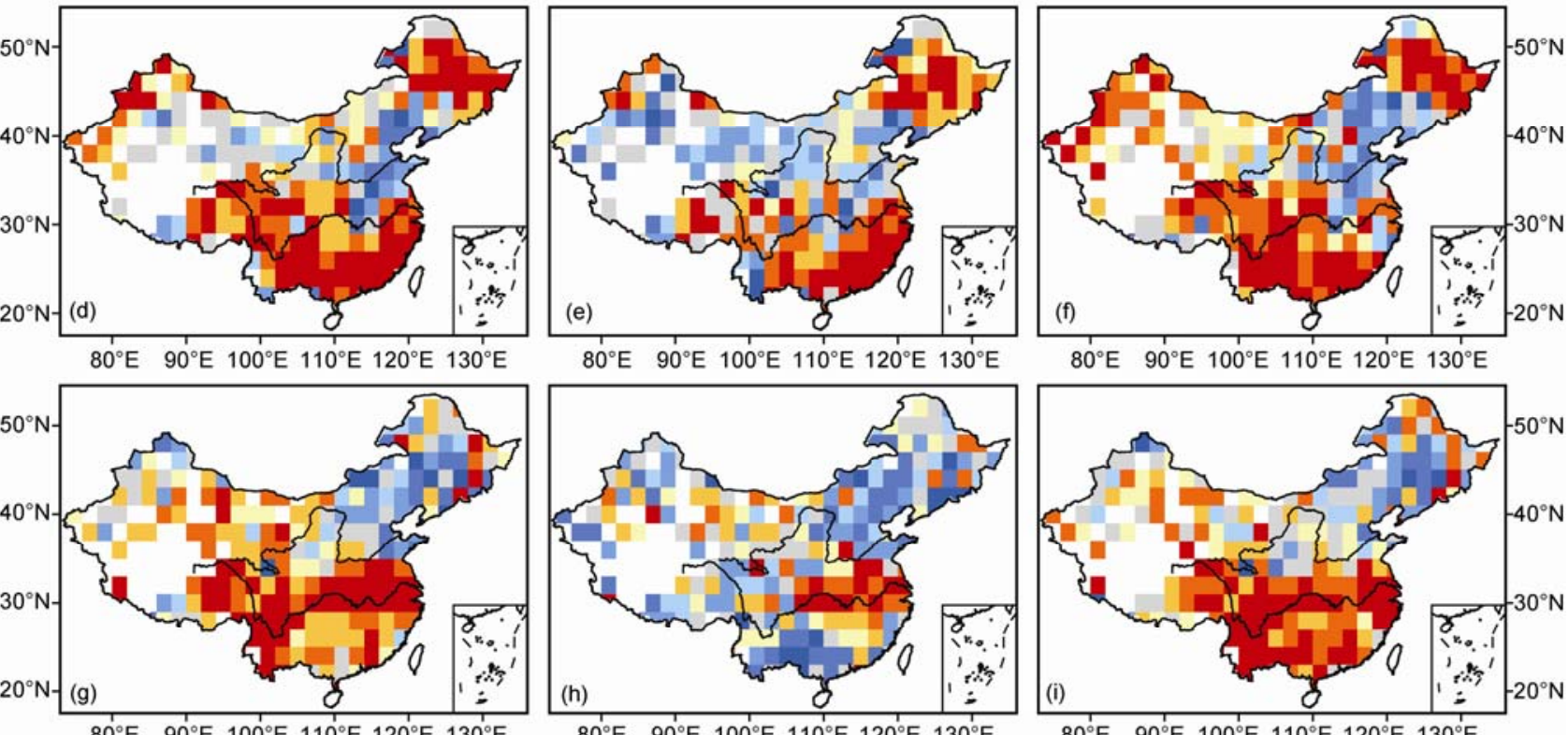

$80^{\circ} \mathrm{E} \quad 90^{\circ} \mathrm{E} 100^{\circ} \mathrm{E} 110^{\circ} \mathrm{E} 120^{\circ} \mathrm{E} 130^{\circ} \mathrm{E}$

$80^{\circ} \mathrm{E} \quad 90^{\circ} \mathrm{E} 100^{\circ} \mathrm{E} 110^{\circ} \mathrm{E} 120^{\circ} \mathrm{E} 130^{\circ} \mathrm{E}$
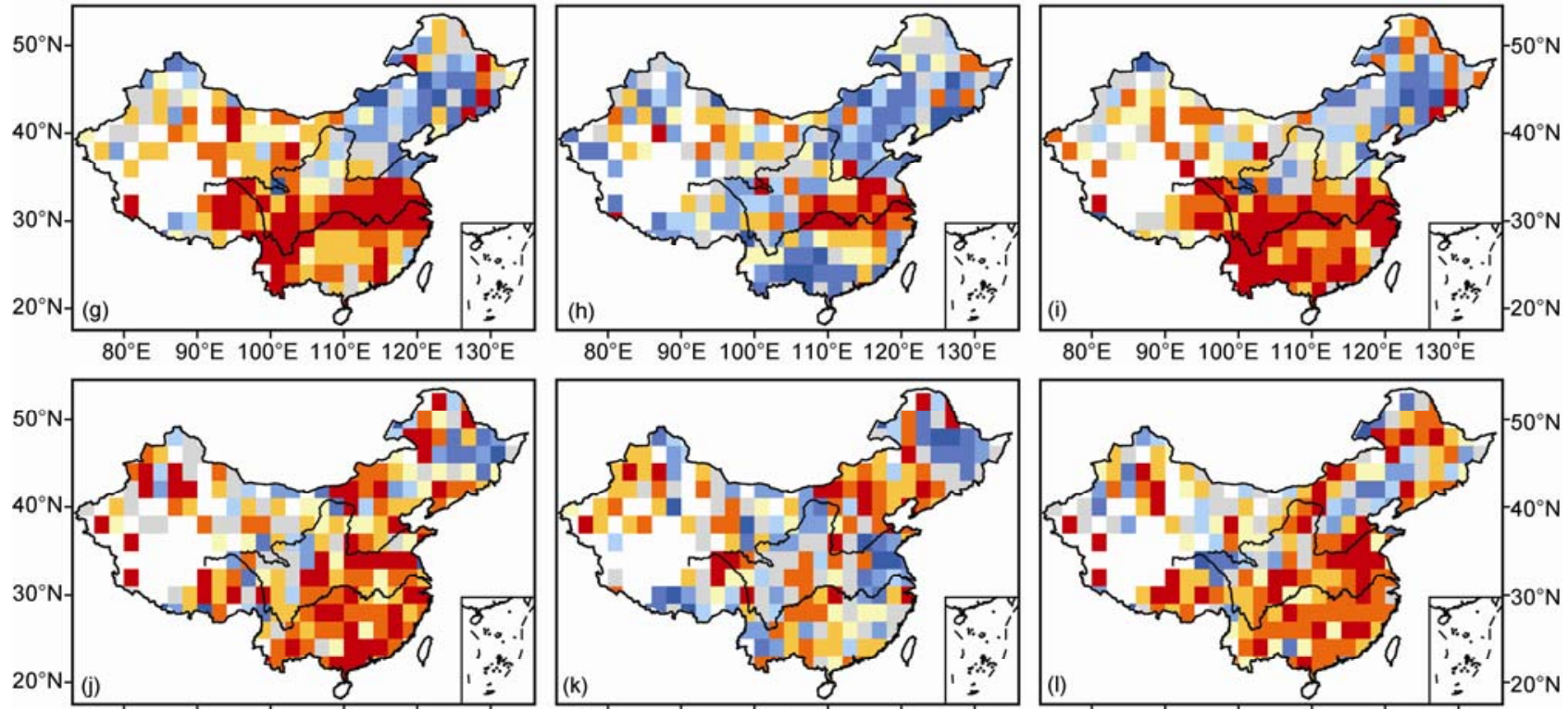

$80^{\circ} \mathrm{E} \quad 90^{\circ} \mathrm{E} 100^{\circ} \mathrm{E} 110^{\circ} \mathrm{E} 120^{\circ} \mathrm{E} 130^{\circ} \mathrm{E}$

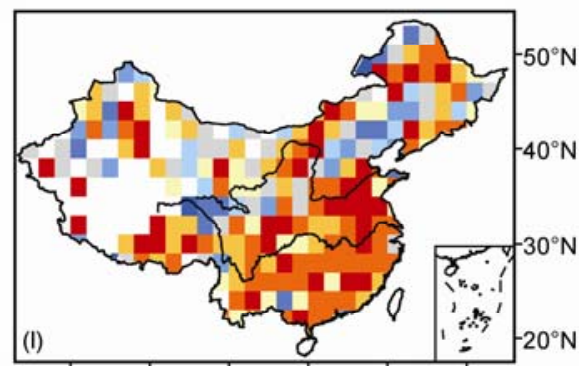

$80^{\circ} \mathrm{E} \quad 90^{\circ} \mathrm{E} 100^{\circ} \mathrm{E} 110^{\circ} \mathrm{E} 120^{\circ} \mathrm{E} 130^{\circ} \mathrm{E}$

$80^{\circ} \mathrm{E} \quad 90^{\circ} \mathrm{E} \quad 100^{\circ} \mathrm{E} 110^{\circ} \mathrm{E} 120^{\circ} \mathrm{E} 130^{\circ} \mathrm{E}$

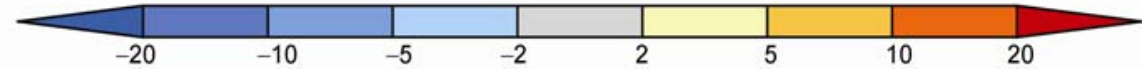

Figure 2 Seasonal mean of monthly percentages of the variance of the mean daily maximum (left panel), minimum (middle panel) and diurnal range (right panel) of surface air temperature owing to vegetation feedback for the period 1982-2002: (a)-(c) DJF; (d)-(f) MAM; (g)-(i) JJA; (j)-(l) SON. The negative values are for the feedback parameter $\lambda_{T}<0$. 
temperatures during or after its existence. In addition, winter snow may play an important role in influencing grassland and desert vegetation growth over China [25]. The effects of other land surface parameters cannot be separated from the effects of vegetation itself in this study. The explained variances may partly reflect the effects of other land surface parameters.

\section{Conclusions and discussion}

This study statistically assesses local vegetation effects on $T_{\max }$ and $T_{\min }$ from the observations using a statistical method that isolates the vegetation feedback signal from the atmospheric noise. In all seasons, vegetation effects are found to be much stronger for $T_{\max }$ than for $T_{\min }$. As a result, the spatial patterns and strengths of vegetation feedbacks on the DTR largely depend on the vegetation effects on $T_{\max }$. For both $T_{\max }$ and the DTR, positive feedbacks dominate with many areas achieving a confidence level of $P<0.1$. In contrast, significant negative feedbacks only appear over the summertime climatic and ecological transition zone of northern China and some other isolated areas. Vegetation effects on $T_{\min }$ are smaller and less significant than those on $T_{\max }$ and the DTR in all seasons. In addition, positive feedbacks occupy smaller areas. Furthermore, large seasonal variations are evident for the vegetation feedbacks on the three temperature variables. In areas where significant feedbacks are identified, vegetation variations contribute to typically $10 \%-30 \%$ of the total variances with the feedback strengths generally exceeding $1^{\circ} \mathrm{C}(0.1 \mathrm{NDVI})^{-1}$. Meanwhile, the limitations and uncertainties of the study should be recognized and further addressed.

Asymmetric effects of vegetation on $T_{\max }$ and $T_{\min }$ result from the diurnal asymmetry in its effects on the surface energy balance. An increase in vegetation tends to decrease surface albedo versus either snow-covered or snow-free ground, thus increasing the absorbed solar radiation during the daytime. The positive vegetation feedbacks on daytime $T_{\max }$ may mainly reflect the effects of vegetation-induced changes in surface albedo. Significant negative feedbacks on $T_{\max }$ also exist over the summertime climatic and ecological transition zone of northern China and some other isolated areas. The negative feedbacks may be achieved through the larger negative effects of enhanced evaporative cooling than the positive effects of decreased surface albedo corresponding to an increase in vegetation. Based on climate model simulations, Zhou et al. [26] demonstrated that a reduction in vegetation cover can increase nighttime $T_{\min }$ over arid and semiarid regions through increased soil heating and reduced outgoing longwave radiation. There are large arid and semiarid areas in China with low vegetation coverage. Such an effect may account for the negative feedbacks to $T_{\min }$ over the arid and semiarid regions. The negative feedbacks on $T_{\min }$ are also seen in some relatively humid areas, and they may result from the dominant effects of evaporative cooling. The daytime temperature largely affects the nighttime temperature. Over regions where vegetation exerts positive effects on both $T_{\max }$ and $T_{\min }$, vegetation feedbacks on $T_{\min }$ may be closely related to its effects on the daytime temperature. In addition, the asymmetric effects of vegetation on $T_{\max }$ and $T_{\min }$ may be due to some indirect mechanisms such as changes in the diurnal course of cloud cover and/or cloud properties and atmospheric water vapor. The proposed physical mechanisms clearly need to be further clarified using process-based approaches such as simulation with regional climate models in the future [27-33].

Since the land surface, in particular vegetation and soil moisture, can "remember" an atmospheric anomaly for months and more, land-atmosphere interactions may hold the key for improving seasonal forecasting. Recent works have highlighted the role of soil moisture in triggering monthly to seasonal atmospheric predictability over mid-latitude land areas [21,34-36]. Our findings together with those of previous studies [7,8] suggest the importance of exploiting vegetation-atmosphere interactions for enhanced monthly and seasonal predictability of mean temperature, $T_{\max }$, and $T_{\min }$ variability, and the associated temperature extremes over China.

We would like to thank two anonymous reviewers for their insightful comments. This work was supported by the Hundred Talent Program of the Chinese Academy of Sciences, the Special Fund for President's Prize of the Chinese Academy of Sciences and the National Basic Research Program of China (2009CB421405).

1 Pielke R A, Avissar R, Raupack M, et al. Interactions between the atmosphere and terrestrial ecosystems: Influence on weather and climate. Glob Change Biol, 1998, 4: 461-475

2 Bonan G B. Ecological Climatology. New York: Cambridge University Press, 2008

3 Brovkin V, Ganopolski A, Claussen M, et al. Modelling climate response to historical land cover change. Glob Ecol Biogeogr, 1999, 8: 509-517

4 Davin E L, de Noblet-Ducoudre N. Climatic impact of global-scale deforestation: Radiative versus nonradiative processes. J Clim, 2010, 23: $97-112$

5 Dirmeyer P A, Koster R D, Guo Z. Do global models properly represent the feedback between land and atmosphere? J Hydrometeorol, 2006, 7: 1177-1198

6 Pitman A J, de Noblet-Ducoudre N, Cruz F T, et al. Uncertainties in climate responses to past land cover change: First results from the LUCID intercomparison study. Geophys Res Lett, 2009, 36: L14814, doi:10.1029/2009GL039076

7 Zhang J, Dong W, Fu C, et al. The influence of vegetation cover on summer precipitation in China: A statistical analysis of NDVI and climate data. Adv Atmos Sci, 2003, 20: 1002-1006

8 Liu Z, Notaro M, Kutzbach J, et al. Assessing global vegetation-climate feedbacks from observations. J Clim, 2006, 19: 787-814

9 Hua W, Fan G, Zhou D, et al. Preliminary analysis on the relationships between Tibetan Plateau NDVI change and its surface heat source and precipitation of China. Sci China Ser D-Earth Sci, 2008, 51: 677-685

10 Wang $\mathrm{Y}$, Zhao $\mathrm{P}, \mathrm{Yu} \mathrm{R}$, et al. Inter-decadal variability of Tibetan 
spring vegetation and its associations with eastern China spring rainfall. Int J Climatol, 2010, 30, doi: 10.1002/joc.1939

11 Zuo Z, Zhang R, Zhao P. The relation of vegetation over the Tibetan Plateau to rainfall in China during the boreal summer. Clim Dyn, 2010, doi: 10.1007/s00382-010-0863-6

12 Zhang J, Dong W, Ye D, et al. New evidence for effects of land cover in China on summer climate. Chinese Sci Bull, 2003, 48: 401-405

13 Easterling D R, Meehl G A, Parmesan C, et al. Climate extremes: Observation, modeling and impacts. Science, 2000, 289: 2068-2074

14 Meehl G A, Tebaldi C. More intense, more frequent and longer lasting heat waves in the 21st century. Science, 2004, 305: 994-997

15 Pinzon J, Brown M E, Tucker C J. Satellite time series correction of orbital drift artifacts using empirical mode decomposition. In: Huang N E, ed., NASA Goddard Space Flight Cent., Greenbelt, MD, Hilbert-Huang Transform: Introduction and Applications 2004, 173-176

16 Tucker C J, Pinzon J E, Brown M E, et al. An extended AVHRR 8-km NDVI data set compatible with MODIS and spot vegetation NDVI data. Int J Remote Sens, 2005, 26: 4485-4498

17 Li Q, Zhang H, Chen J, et al. A mainland China homogenized historical temperature dataset of 1951-2004. Bull Am Meteorol Soc, 2009, 90: 1062-1065

18 Frankignoul C, Hasselmann K. Stochastic climate models: Part 2. Application to sea surface temperature anomalies and thermocline variability. Tellus, 1977, 29: 289-305

19 Frankignoul C, Czaja A, L'Heveder B. Air-sea feedback in the North Atlantic and surface boundary conditions for ocean models. J Clim, 1998, 11: 2310-2324

20 Liu Z, Wu L. Atmospheric response to North Pacific SST: The role of ocean-atmosphere coupling. J Clim, 2004, 17: 1859-1882

21 Zhang J, Wang W C, Wei J. Assessing land-atmosphere coupling using soil moisture from the Global Land Data Assimilation System and observational precipitation. J Geophys Res, 2008, 113, doi:10.1029/ 2008JD009807

22 Von Storch H, Zwiers F W. Statistical Analysis in Climate Research. New York: Cambridge University Press, 1999

23 Notaro M, Wang Y, Liu Z, et al. Combined statistical and dynamical assessment of simulated vegetation-rainfall interactions in North Africa during the mid-Holocene. Glob Change Biol, 2008, 14: 347-368

24 Notaro M, Liu Z. Statistical and dynamical assessment of vegetation feedbacks on climate over the boreal forest. Clim Dyn, 2008, 31, doi:10.1007/s00382-008-0368-8

25 Peng S, Piao S, Ciais P, et al. Change in winter snow depth and its impacts on vegetation in China. Glob Change Biol, 2010, 16: 30043013

26 Zhou L, Dickinson R E, Tian Y, et al. Impact of vegetation removal and soil aridation on diurnal temperature range in a semiarid region: Application to the Sahel. Proc Natl Acad Sci USA, 2007, 104: 17937-17942

27 Fu C, Yuan H. An virtual numerical experiment to understand the impacts of recovering natural vegetation on the summer climate and environmental conditions in East Asia. Chinese Sci Bull, 2001, 46: 1199-1203

28 Gao X J, Luo Y, Lin W T, et al. Simulation of effects of landuse change on climate in China by a regional climate model. Adv Atmos Sci, 2003, 20: 583-592

29 Wang H J, Zhou H. A simulation study on the eco-environmental effects of 3N shelterbelt in North China. Glob Planet Change, 2003, 37: 231-246

30 Zheng Y Q, Qian Y F, Miao M Q, et al. The effects of vegetation change on regional climate I : Simulation results (in Chinese). Acta Meteorol Sin, 2002, 60: 1-16

31 Zhang J, Dong W, Fu C. Impact of land surface degradation in northern China and southern Mongolia on regional climate. Chinese Sci Bull, 2005, 50: 75-81

32 Chen J M, Zhao P, Liu H L, et al. Modeling impacts of vegetation in western China on the summer climate of northwestern China. Adv Atmos Sci, 2009, 26: 803-812

33 Zhang J, Cha D H, Lee D K. Investigating the role of MODIS leaf area index and vegetation-climate interaction in regional climate simulations. Terr Atmos Ocean Sci, 2009, 20: 377-393

34 Koster R D, Dirmeyer P A, Guo Z, et al. Regions of strong coupling between soil moisture and precipitation. Science, 2004, 305: 11381140

35 Zuo Z, Zhang R. The spring soil moisture and the summer rainfall in eastern China. Chinese Sci Bull, 2007, 52: 3310-3312

36 Conil S, Douville H, Tyteca S. Contribution of realistic soil moisture initial conditions to boreal summer climate predictability. Clim Dyn, 2009, 32: 75-93

Open Access This article is distributed under the terms of the Creative Commons Attribution License which permits any use, distribution, and reproduction in any medium, provided the original author(s) and source are credited. 